\title{
CLINICOPATHOLOGICAL PROFILE AND SURGICAL MANAGEMENT OUTCOMES IN PATIENTS SUFFERING FROM INTESTINAL TUBERCULOSIS
}

\author{
M. Jawaid Rajput, Abdul Sattar Memon, Shabnam Rani and Adeel Hamad Memon
}

\begin{abstract}
OBJECTIVES: To determine the mode of presentation in intestinal tuberculosis and effectiveness of various surgical procedures adopted in our set up.

DESIGN: A descriptive study.

SETTING: Liaquat University Hospital, Hyderabad from June 1996 to May 1998 and Muhammad Medical College Hospital Mirpurkhas, Sindh from April 2002 to March 2004.

METHODS: One hundred-twelve cases of intestinal tuberculosis were studied, which were operated and diagnosis was confirmed on biopsy. Data collection included detailed history particularly duration of symptoms, respiratory complains, dietary habits and bowel habits. At Liaquat University Hospital, 1872 patients were admitted, 386 (20.61\%) were operated for abdominal complains (acute, sub-acute or chronic intestinal obstruction or perforation) and $80(4.27 \%)$ were diagnosed as having intestinal tuberculosis.

Meanwhile, 624 patients were admitted in Muhammad Medical College Hospital Mirpurkhas. Of these, one hundred-seventy (27.24\%) were operated for abdominal pathology and $32(5.12 \%)$ cases were proved as intestinal tuberculosis on histopathology.

RESULTS: Out of total 112 cases of intestinal tuberculosis, $64(57.20 \%)$ were male and 48 $(42.80 \%)$ females. Age ranged from 8 to 55 years with majority in 2nd and 3rd decades. Resection and anastomosis of small gut, limited right hemicolectomy, right hemicolectomy, stricturoplasty, ileostomy, adhenolysis and evacuation of pus were the procedures adopted for management. Post-operative complications were seen in $30.65 \%$ of patients with wound infection on top, however, mortality remained $3.57 \%$.

CONCLUSION: The mortality of intestinal tuberculosis is high due to delay in diagnosis and under dosage or irregular anti-tuberculous treatment. In complicated cases, surgery is indicated. When multiple strictures or perforations are present, resection and end to end anastomosis is required. In case of caecal mass (fungating type), right hemicolectomy can be performed and in cases where extensive adhesions are present and there is fear of iatrogenic perforation, in attempts to mobilize right colon, limited right hemicolectomy shall be performed.
\end{abstract}

KEY WORDS: Tuberculosis. Intestine. Management. Surgery.

\section{INTRODUCTION}

Mycobacterium tuberculosis is the most important human pathogen today, and tuberculosis is the leading cause of death due to any single infectious agent world wide. ${ }^{1}$ This disease is as ancient as the mankind. It was known to Hippocrates who gave it the name of phthisis, which means wasting disease. ${ }^{2}$

It was also called "captain of all the men's deaths" and "great white plague in ancient times". ${ }^{3}$ The tubercle bacilli are non-sporing immobile, aerobic gram positive and acid fast bacteria. ${ }^{4}$ In populations where milk supply continues to be contaminated with tubercle bacilli, or pulmonary or other forms of tuberculosis are endemic, intestinal tuberculosis is still prevalent. $^{5}$
According to World Health Organization estimate in 1999, there were 8.4 million new cases of tuberculosis in comparison to 8.0 million in $1997 .{ }^{6}$ Approximately 2 billion people, nearly one-third of world's population are infected with mycobacterium tuberculosis. ${ }^{7}$ Western countries enjoyed a long decline in the rate of mycobacterium tuberculosis infection and death until the mid 1980's. Since that time, tuberculosis has been increasing in Europe and Africa in part because it frequently and dramatically infects persons with AIDs. ${ }^{8}$ Abdomen is a common site of involvement. It usually affects children and young adults and is more common in females. ${ }^{9}$ Intestinal tuberculosis is common in the remote areas of Sindh, where under 
nutrition, poverty, over crowding and worst living standards contribute to the problem. Most cases remain undiagnosed until they develop complication, where surgery is the only hope. Even if it is suspected before development of complication medical therapy may result in healing by fibrosis leading to the intestinal obstruction.

\section{PATIENTS AND METHODS}

One hundred - twelve cases of intestinal tuberculosis were admitted, operated and diagnosis was confirmed on biopsy at Department of Surgery (unit one) of Liaquat Medical College Hospital Hyderabad from June 1996 to May 1998 and Department of Surgery Muhammad Medical College Hospital Mirpurkhas from April 2002 to March 2004. Details of all the cases were recorded particulary duration of symptoms, respiratory complains, dietary habits and bowel habits. Physical examination and digital rectal examination were performed as routine in each case presenting with signs and symptoms of acute, sub acute or chronic bowel obstruction. Various surgical procedures were adopted including resection and anastomosis, limited right hemicolectomy, right hemicolectomy, adhenolysis with evacuation of abscess and mesenteric lymph node biopsy, stricturoplasty and ileostomy. Morbidity was based on post-operative complications including wound infection, chest infection, septicemia, faecal fistula etc. Frequencies regarding age and sex, clinical features, investigations etc. were also calculated from the information gathered on the proforma.

\section{RESULTS}

During four years study period, total 2496 cases were admitted in two surgical units. At Liaquat Medical College Hospital, total number of cases admitted was 1872. Out of these, $386(20.61 \%)$ cases were operated and intestinal tuberculosis was diagnosed in $80(4.27 \%)$ cases. At Muhammad Medical College Hospital, total number of cases admitted was 624 and $170(27.24 \%)$ cases were operated. Among these, intestinal tuberculosis was found in $32(5.12 \%)$ patients. Out of total 2496 patients, 556 (20.22\%) were operated for abdominal signs and symptoms (acute, sub-acute and chronic intestinal obstruction; perforation and mass in right iliac fossa). Out of these, $112(4.48 \%)$ patients were diagnosed on histopathology to have intestinal tuberculosis. Sixtyfour $(57.20 \%)$ cases were male and $48(42.80 \%)$ females. Age ranged from 8 to 55 years and majority belonged to $2^{\text {nd }}$ and $3^{\text {rd }}$ decades (Table I). Out of 112 cases, 72 were received in surgical emergency and 40 presented in out patients department (OPD). Fourtytwo $(37.50 \%)$ had acute intestinal obstruction while acute peritonitis was observed in $26(23.21 \%)$ cases. Four patients $(3.57 \%)$ presented with history of frequent episodes of pain in right iliac fossa and were diagnosed initially as recurrent appendicitis. Out of 40 patients who presented in OPD, $24(21.42 \%)$ had chronic vague abdominal pain with altered bowel habits while $16(14.28 \%)$ had pain and palpable masses in the right iliac fossa. Associated symptoms included weight loss in 66 (58.92\%) patients, anorexia in $76(67.85 \%)$ and night sweats in $28(25.0 \%)$ cases while constipation alternating with diarrhea was present in $36(32.12 \%)$ cases. Abnormalities most frequently encountered on physical examination were tender abdomen in 84 patients $(76.78 \%)$, distension of abdomen with vomiting $68(60.71 \%)$, low-grade pyrexia in $68(60.71 \%)$, ascites in $32(28.57 \%)$ and mass in right iliac fossa in $16(14.28 \%)$ cases. Out of total 112 cases, 38 (33.93\%) patients had associated pulmonary tuberculosis. Remaining 74 (66.07\%) patients had no other form of tuberculosis. Mean haemoglobin level in the cases was $9.5 \mathrm{gm} \%$. Details regarding investigations performed in these cases are given in Table II. Apart from the investigations which were carried out in these patients, other investigations like TB-GA test ${ }^{10}$, serological test (compliment fixation $)^{11}$, polymerase chain reaction assay ${ }^{12}$, gastric and external washing for $\mathrm{AFB}^{13}$ and guinea pig inoculation ${ }^{14}$ have also been recommended. Mode of management remained emergency surgery in 72 patients who presented in emergency along with frequent urgent resuscitation. Remaining 40 cases had chronic signs and symptoms and were operated electively after thorough investigations.

On laparotomy, ulcerostenotic type of lesion involving small intestine was found in 46 cases. In 14 cases, ileal perforation was also present along with ulcerostenotic lesion. Hypertrophic variety was observed in 26 cases where as strictures along with small bowel adhesions were found in 34 cases. Out of these, two cases had multiple strictures in proximal jejunum and rest of the gut was normal. Abdominal abscesses along with adhesion of gut loops and mesenteric lymph node hypertrophy were found in 6 cases.

Resection and anastomosis of small gut was performed in 66 cases $(58.92 \%)$, limited right hemicolectomy in $22(19.64 \%)$ cases and classical right hemicolectomy in $12(10.71 \%)$ cases. lleostomy was performed in $2(1.78 \%)$ cases, which was closed after 6 weeks time (Table III). Post-operative complications were encountered in 42 patients 
M. Jawaid Rajput, Abdul Sattar Memon, Shabnam Rani, et al

(37.5\%), of which the major share was contributed by wound infection (Table IV). Four patients died due to septicemia and pulmonary complications making overall mortality of $3.57 \%$.

TABLE I:

AGE DISTRIBUTION OF CASES $(n=112)$

\begin{tabular}{|c|c|c|}
\hline Age (years) & Number of patients & Percentage \\
\hline $1-10$ & 12 & 10.71 \\
\hline $11-20$ & 28 & 25.00 \\
\hline $21-30$ & 36 & 32.14 \\
\hline $31-40$ & 20 & 17.85 \\
\hline $41-50$ & 8 & 7.14 \\
\hline $51-60$ & 8 & 7.14 \\
\hline
\end{tabular}

TABLE III:

SURGICAL PROCEDURES PERFORMED IN PATIENTS WITH INTESTINAL TUBERCULOSIS

\begin{tabular}{|l|c|c|}
\hline \multicolumn{1}{|c|}{ Procedure } & $\begin{array}{c}\text { Number of } \\
\text { patients }\end{array}$ & Percentage \\
\hline $\begin{array}{l}\text { Resection and end to } \\
\text { end anastomosis }\end{array}$ & 66 & 58.92 \\
\hline Limited right hemicolectomy & 22 & 19.64 \\
\hline Right hemicolectomy & 12 & 10.71 \\
\hline $\begin{array}{l}\text { Adhenolysis and } \\
\text { evacuation of pus }\end{array}$ & 6 & 5.35 \\
\hline Stricturoplasty & 4 & 3.57 \\
\hline $\begin{array}{l}\text { lleostomy with closure } \\
\text { of ileostomy (6 weeks) }\end{array}$ & 2 & 1.78 \\
\hline
\end{tabular}

TABLE II:

LABORATORY FINDINGS IN PATIENTS OF INTESTINAL TUBERCULOSIS

\begin{tabular}{|c|c|c|}
\hline Investigation & Number of patients & Percentage \\
\hline \multicolumn{3}{|l|}{ Blood Complete picture $(n=112)$} \\
\hline Raised erythrocyte sedimentation rate & 96 & $85.48 \%$ \\
\hline Raised white blood cells count & 44 & $38.92 \%$ \\
\hline Neutrophilia & 30 & $26.78 \%$ \\
\hline Lymphocytosis & 14 & $12.14 \%$ \\
\hline WBC count in normal units & 68 & $60.71 \%$ \\
\hline \multicolumn{3}{|l|}{ Radiological examination, X-ray chest PA view $(n=112)$} \\
\hline - $\quad$ Pulmonary tuberculosis present & 38 & $33.92 \%$ \\
\hline \multicolumn{3}{|l|}{ Plain X-ray abdomen erect and supine postures $(n=112)$} \\
\hline - $\quad$ Dilated bowel loops with air fluid levels & 42 & $37.50 \%$ \\
\hline - $\quad$ Free gas under right dome of diaphragm & 14 & $12.14 \%$ \\
\hline \multicolumn{3}{|l|}{ Barium enema $(n=16)$} \\
\hline - $\quad$ Loss of cacial shadow & 6 & $37.5 \%$ \\
\hline \multicolumn{3}{|l|}{ Ultrasound examination $(n=40)$} \\
\hline - $\quad$ Mass in right iliac fossa & 16 & $40 \%$ \\
\hline \multicolumn{3}{|l|}{ Colonoscopy $(n=8)$} \\
\hline - Intraluminal mass in caecum & 8 & $100 \%$ \\
\hline \multicolumn{3}{|l|}{ Barium meal follow through $(n=8)$} \\
\hline - $\quad$ Stenotic lesion in small intestine & 2 & $25 \%$ \\
\hline $\begin{array}{l}\text { Histopathology of resected intestinal segment and mesenteric } \\
\text { lymph node showing langhan giant cell and caseation necrosis }\end{array}$ & 112 & $100 \%$ \\
\hline
\end{tabular}


TABLE IV:

POST-OPERATIVE COMPLICATIONS IN INTESTINAL TUBERCULOSIS

\begin{tabular}{|l|c|c|}
\hline \multicolumn{1}{|c|}{ Complication } & $\begin{array}{c}\text { Number of } \\
\text { patients }\end{array}$ & Percentage \\
\hline Wound infection & 26 & $23.21 \%$ \\
\hline Chest infection & 6 & $5.35 \%$ \\
\hline Septicemia & 4 & $3.57 \%$ \\
\hline Enterocutaneous fistula & 4 & $3.57 \%$ \\
\hline Incisional hernia & 2 & $1.78 \%$ \\
\hline
\end{tabular}

\section{DISCUSSION}

Intestinal tuberculosis is uncommon in the west but is still prevalent in developing countries ${ }^{16}$ where diagnostic and treatment facilities are rudimentary or non-existent. ${ }^{17,18}$ In Pakistan, tuberculosis has been reported as the second commonest cause of intestinal obstruction. ${ }^{19}$ The age distribution of patients in this series ranged from 8 to 55 years with peak incidence in $3^{\text {rd }}$ decade. This very well correlates with national and international studies. ${ }^{19-21}$ Similarly, sex ratio was almost equal (1.3:1) with slight male predominance like one study from Japan ${ }^{16}$, but contrary to other studies. ${ }^{20,22,23}$ In this study, $42(37.50 \%)$ cases presented with signs and symptoms of acute intestinal obstruction. This data also coincides with other studies ${ }^{19,24}$ However, 26 (23.21\%) patients presented with acute abdomen and on laparotomy, small bowel perforation was observed in 14 cases either as a solitary lesion or proximal to a stenotic lesion, which is consistent with a report from United Kingdom. ${ }^{25}$ Although, intestinal tuberculosis may present with a variety of non-specific abdominal features, the most common primary complain in this series was colicky central abdominal pain and dyspepsia in 24(21.42\%) patients which is contrary to the findings of Schulze $K$ et $\mathrm{al}^{26}$, where this figure was $35 \%$. Mass and pain in right iliac fossa were found in $16(14.28 \%)$ patients in this study which is quite different from the data of Underwood $\mathrm{MJ}$ et $\mathrm{al}^{21}$ and Singh $\mathrm{A}$ et $\mathrm{al}^{27}$, where abdominal mass remained $35 \%$ and $52 \%$ respectively. These masses may be formed due to hypertrophic ileocaeceal lesion or a mass of lymph nodes, adherent omentum or located ascites. ${ }^{20,28}$ Associated symptoms including weight loss were present in 66 patients $(58.92 \%)$, anorexia in $76(67.85 \%)$, night sweats in $28(25 \%)$ and vomiting alternating with diarrhea in $36(32.12 \%)$ cases which is similar to other regional studies. ${ }^{19,29,30}$ The findings most frequently encountered on physical examination were tenderness of abdomen; guarding and rigidity in 84 $(76.78 \%)$ patients, which was generalized in majority of cases. These observations also very well correlate with studies available in the literature. ${ }^{21,22,31}$ Preexisting pulmonary tuberculosis was observed in only $38(33.95 \%)$ patients, consistent with other studies. ${ }^{32-34}$ There are reported cases of duodenal ${ }^{35}$ and oesophageal ${ }^{36}$ tuberculosis. However, no such lesion was found in this study. Commonest sites of involvement were terminal ileum and ileocaecal region followed by jejunum and colon. But, multiple sites are also common ${ }^{37}$. Resection and anastomosis of small gut was performed in majority of this series followed by limited right hemicolectomy and classical right hemicolectomy. In cases where extensive adhesions were present and there was fear of iatrogenic perforation, in attempts to mobilize right colon, limited right hemicolectomy was performed. Stricturoplasty (the defect opened out longitudinally and closure done across the transverse axis of the bowel) was performed in $4(3.5 \%)$ cases. In intestinal tuberculosis involving small intestine in the form of single stricture, stricturoplasty is an option, however, when multiple strictures or perforation is present resection and end to end anastomosis is required. Remaining cases were dealt by adhenolysis, evacuation of pus and mesenteric lymph nodes biopsies. This all very well coincides with the data of other studies ${ }^{38}$. lleostomy was performed in 2 cases primarily and in 2 cases after development of enterocutaneous fistula in whom resection and end to end anastomosis was performed initially. On operation, the most common variety of intestinal tuberculosis was found to be ulcerostenotic comprising of $46(41.07 \%)$ patients. Almost same data $(40 \%)$ is also reported by a regional study ${ }^{28}$. Stenotic tuberculous lesion seems to be due to granulomatous involvement of mesenteric vessels either by intraluminal thrombi or perivascular cuffing leading to gut ischemia, which may contribute to the development of stricture. $^{39}$ Stenosis alongwith adhesions remained the second most common finding on laparotomy comprising of 34 cases (30.35\%). Adhenolysis along with resection is the recommended option $^{22}$ and same was done in these cases. However, laparo-assisted ileo-caceal resection is an alternative to classical surgery. ${ }^{40}$ Post-operative complications occurred in $42(36.71 \%)$ cases in this series. The major share was contributed by wound infection, which was observed in 26 (23.21\%) patients especially in those who had bowel perforation, and it is comparable with other studies ${ }^{41}$ In this series, chest complications were observed in 6 patients (5.35\%). They all had pre-existing pulmonary tuberculosis and were operated in emergency. Enterocutaneous fistula was seen in $4(3.35 \%)$ cases; $2(1.78 \%)$ were of low output type and settled on conservative therapy. In remaining 2, ileostomy was performed as they were of high type but they expired in few days due to 
development of multiorgan failure. Two patients who were brought in terminal stage and were found to be having bowel perforation for a couple of days were operated in emergency after due resuscitation. They undergone ileostomy but died due to septicemia. In this way, mortality occurred in total 4 cases $(3.57 \%)$, which is consistent with other studies ${ }^{42}$. Incisional hernia developed in two cases (1.78\%); of midline laparotomy incision, which were repaired later on. Anti-tuberculous chemotherapy was given in all cases post-operatively. ${ }^{22,43}$ In countries with a high prevalence of intestinal tuberculosis like Pakistan, a therapeutic trial of anti-tuberculous drugs may be reasonable if the clinical picture is compatible. ${ }^{42}$ In this series, majority of patients $70(62.50 \%)$ stayed in the hospital for 7-14 days. The patients whose stay exceeded up to 6 weeks were those who developed post-operative complications.

\section{CONCLUSION}

The diagnosis of intestinal tuberculosis is difficult to establish as it may present a wide variety of nonspecific features. In intestinal tuberculosis involving small intestine in the form of single stricture, stricturoplasty is an option, however, when multiple strictures or perforations are present, resection and end to end anastomosis is required. In case of caecal mass (fungating type), right hemicolectomy can be performed and in cases where extensive adhesions are present and there is fear of iatrogenic perforation, in attempts to mobilize right colon, limited right hemicolectomy can be performed. Despite recent advances in surgery and the availability of specific anti-tuberculous chemotherapy, the mortality of intestinal tuberculosis is high due to delay in diagnosis and under dosage or irregular anti-tuberculous treatment. It can be reduced only by timely diagnosis and judicious treatment.

\section{REFERENCES}

1. Butt T, Ahmed RN, Syed YK, et al. An update on the diagnosis of tuberculosis. J Coll Physicians Surg Pak 2003; 12: 728-33.

2. Sherman S, Rohwedder JJ, Ravikrishman KP, et al. Tuberculous enteritis and peritonitis: report of 36 general cases. Arch Intern Med 1980; 140: 306-8.

3. Addison NV. Abdominal tuberculosis: a disease revisited. Ann R Coll Surg Eng 1983; 65: 105-11.

4. Mackie and McCartney. Practical Medical Microbiology Vol. I. 13 ${ }^{\text {th }}$ Edition, 1985;p. 286.

5. Fielding LP and Peronikoff BJ. Hamilton Bailey's emergency surgery. 12th Edition. 1995; 425.

6. World Health Organization, WHO report 2001. Global tuberculosis control. Geneva: World Health Organization, 2001.
7. Dolin PJ, Raviglione MC, Kochi A. Global tubrculosis incidence and mortality during 19902000. Bull World Health Organ 1994; 72: 213-20.

8. Daley CL. An outbreak of tuberculosis with acceleration progression among persons infected with the human immunodeficiency virus. $\mathrm{N}$ Eng J Med 1992:326-231.

9. Abro HA, Rukhsana, Ara J, Hussain S. Abdominal tuberculosis: presentation and early diagnosis. J Surg Pak 1998;3:2-5.

10. Larsson S, Shrestha MP, Pakhrel BM. The glutaraldehyde test as a rapid screening method for pulmonary tuberculosis: a preliminary report. Ann Trop Med Parasitol 1990; 111-117.

11. Middlebrook G, Dubos RJ. Specific serum agglutination of erythrocytes sensitized with extract of tubercle bacilli. J Exper Med 1948; 6-8, 521.

12. Gan H, Ouyang Q. The value of polymerase chain reaction in the diagnosis of intestinal tuberculosis. Chung Hua Nei Ko-TSA. Chih China 1995; 34 (1): 30-3.

13. Ives JGJ, McCormick WA. Modification of sutas method of cultivation of tubercle bacilli from pleural fluid. J Clin Pathol 1956;9:717.

14. Swain Rtta, Marmion Duguid JP. In: Mackie and McCartney's Medical Microbiology Vol. I, $13^{\text {th }}$ edition. 1985; p. 290-93.

15. Shah P. Ramakantan R. Role of vasculites in the natural history of abdominal tuberculosis: evaluation by mesenteric angiography. Indian $\mathrm{J}$ Gastroenterol 1991;10(4): 27-3.

16. Ahmed M, Mughal MA, Maingal MA. Varied intestinal tuberculosis: an experience at Sandeman Hospital, Quetta. J Coll Physicians Surg Pak 2000; 10: 246-8.

17. World Health Organization. WHO report on the tuberculosis epidemic. Geneva: World Health Organization; 1997.

18. Butt T, Karamat KA, Ahmed RN, et al. Advances in diagnosis of tuberculosis [Editorial]. Pak J Pathol 2001;12: 1-3.

19. Afshan Z, Abrar M, Qureshi MI. Comparison between stricture plasty and resection anastomosis in tuberculous intestinal strictures. J Coll Physicians Surg Pak 2003;5: 277-9.

20. Das $P$, Shukla HS. Clinical diagnosis of abdominal tuberculosis. Br J Surg 1976; 63: 9416.

21. Underwood MJ, Thompson MM, Sayars RD, et al. Presentation of abdominal tuberculosis to general surgeon. Br J Surg 1992; 79: 1077-9.

22. Kapoor VK, Sharma LK. Abdominal tuberculosis. Br J Surg 1988; 75: 2-3.

23. Naz F, Chaudhry ZA, Haq AU, et al. Abdominal tuberculosis: a review of 25 cases. Ann K Ed Med 
Coll 1999; 5:180-3.

24. Malik K, Ahmed W. The pattern of intestinal obstruction in Jinnah Postgraduate Medical Centre, Karachi. J Coll Physicians Surg Pak 1991; 1:32-35.

25. Scriven JM, Berry D. Multiple small bowel perforations in a patient on treatment of tuberculosis. J R Coll Surg Edinb. 1996 ;1 (5):353.

26. Schulze K, Warner HA, Munay D. Intestinal tuberculosis: experience at a Canadian teaching institute. Am J Med 1977; 63: 735-45.

27. Singh A, Bansal BC, Sekhon GS, et al. So-called primary abdominal tuberculosis in India. Am J Gastroenterol 1963; 39: 655-66.

28. Vaidya MG, Sodhi JS. Gastrointestinal tract tuberculosis: a study of 102 cases including 55 hemicolectomies. Clin Radiol 1978;29:189-95.

29. Agarwal P, Malpure S, Rajashankar D, et al. Surgical treatment for abdominal tuberculosis: a review of 50 cases. Bombay Hosp J 1999; 41.

30. Tariq NA. Abdominal tuberculosis: the surgical audit of its presentation. Pak J Surg 1993; 9: 826.

31. Haddad FS, Grossain A, Sawaya E, et al. Abdominal tuberculosis. Dis Colon Rectum 1987; 30: 724-33.

32. Pettengell KE, Larsen C, Garb M. Gastrointestinal tuberculosis in patients with pulmonary tuberculosis. QJ Med South Africa 1990;74:303-8.

33. Ihekwaba FN. Abdominal tuberculosis: a study of
881 cases. J R coll Surg Edinb 1993; 38: 293-5.

34. Sircar S, Tanija VA, Kansra V. Epidemiology and clinical presentation of abdominal tuberculosis: a retrospective study. J Indian Med Assoc 1996; 94: 342-4.

35. Nowak B, Laykensch Lager G, Hennerman $\mathrm{KH}$, et al. A case report of duodenal tuberculosis. Disch - Med Wochenscher (German) 1994; 119(5):1416.

36. Basharat $M$, Khokhar N. Primary oesophageal tuberculosis. J Coll Physicians Surg Pak 2004;6:364-5.

37. Tandian HD. Pathology of intestinal tuberculosis. Trop Gastroenterol 1981;2:77-93.

38. Dandapat MC, Mahapatra SK, Nanda N. Surgical management of intestinal tuberculosis. J Indian Medicine 1990; 88 (6): 156-8.

39. Kuwajaerwala NK, Bapat RO, Joshi AS. Mesenteric vasculopathy in intestinal tuberculosis. Indian J Gastroenterol 1997; 16 (4): 134-6.

40. Guyon P, Brostein JA, Gulluch YL, et al. Laproassisted ileocaecal resection. $\mathrm{M} \mathrm{J}$ Chir Paris 1996; 133 (8): 372-5.

41. Shekeeb $S$, Sumoto M. Intestinal obstruction. Am J Surg 1995;130:9-14.

42. Marshal JB. Tuberculosis of gastrointestinal tract and peritoneum. Am J Gastroenterol 1993;88:989-99.

43. Cooke NJ. Treatment of tuberculosis. Br Med J 1985:291-8.

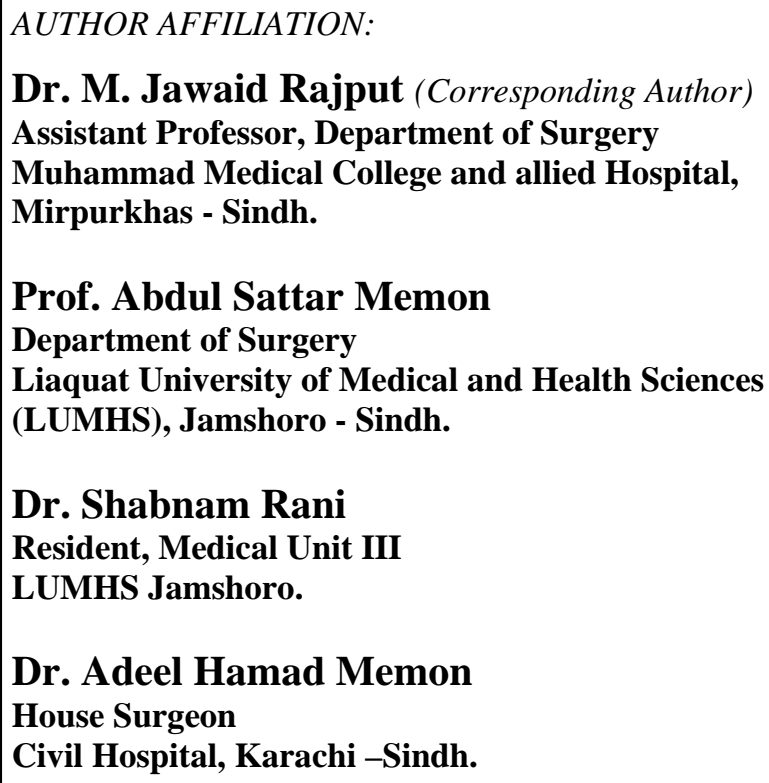

